\title{
Advising complex patients who require complex heart operations
}

\author{
Gösta B. Pettersson, MD, PhD, ${ }^{a}$ Derlis Martino, MD, ${ }^{a}$ Eugene H. Blackstone, MD,,${ }^{\mathrm{a}, \mathrm{b}}$ \\ Edward R. Nowicki, MD, MS, ${ }^{\mathrm{a}}$ Penny L. Houghtaling, MS, ${ }^{\mathrm{b}}$ Joseph F. Sabik III, MD, ${ }^{\mathrm{a}}$ and \\ Bruce W. Lytle, MD
}

Supplemental material is available online.

During the past 4 decades, heart surgery has evolved to encompass increasingly complex operations in increasingly complex patients. Today, patients with multiple noncardiac comorbidities, including old age and organ dysfunction, present with cardiac pathologies requiring multicomponent operations. ${ }^{1-3}$ Yet, because most studies of risk factors focus on isolated procedures, a tool to explain, illustrate, and understand risk and survival is not readily available when patients with multiple comorbidities (complex patients) present for multicomponent heart operations (complex operations).

Furthermore, cardiac surgery programs are evaluated on the basis of subsets of patients undergoing 1-component operations (isolated coronary artery bypass grafting [CABG], isolated aortic valve surgery $[\mathrm{AV}]$, isolated mitral valve surgery $[\mathrm{MV}])$ or simple 2-component operations $(\mathrm{CABG}+\mathrm{AV}, \mathrm{CABG}+\mathrm{MV}){ }^{1-3}$ Risk adjustment is based on factors representing a subset of demographics and common comorbidities. When facing complex patients, we as surgeons use the traditional scores developed for simple operations and extrapolate the patient's risk as best we can, guessing at the contribution of factors not covered by these scores.

Conceptually, it is easy to make a list of factors that contribute to morbidity and mortality after heart surgery. The weight of each factor can only be studied retrospectively; we estimate current risk based on these weights. Learning from experience means learning to master, reduce, or

\footnotetext{
From the Heart and Vascular Institute, ${ }^{a}$ Department of Thoracic and Cardiovascular Surgery, and the Research Institute, ${ }^{\mathrm{b}}$ Department of Quantitative Health Sciences, Cleveland Clinic, Cleveland, Ohio.

This study was supported in part by the Peter and Elizabeth C. Tower and Family Endowed Chair in Cardiothoracic Research, James and Sharon Kennedy, the Slosburg Family Charitable Trust, Stephen and Saundra Spencer, and Martin Nielsen (to Dr Pettersson); and the Kenneth Gee and Paula Shaw, PhD, Chair in Heart Research (to Dr Blackstone).

Disclosures: Authors have nothing to disclose with regard to commercial support.

Received for publication May 24, 2011; revisions received Oct 25, 2012; accepted for publication Nov 9, 2012; available ahead of print Jan 11, 2013.

Address for reprints: Gösta B. Pettersson, MD, PhD, Department of Thoracic and Cardiovascular Surgery, Cleveland Clinic, 9500 Euclid Ave, Desk J4-1, Cleveland, OH 44195 (E-mail: petterg@ccf.org).

J Thorac Cardiovasc Surg 2013;145:1159-69

$0022-5223 / \$ 36.00$

Copyright (c) 2013 by The American Association for Thoracic Surgery

http://dx.doi.org/10.1016/j.jtcvs.2012.11.035
}

neutralize the weight of a given risk factor. ${ }^{4-7}$ Regardless of the sophistication of the statistics, the predictive value is, therefore, limited (as expressed by its confidence limits). No coding system is adequately comprehensive and inclusive, or granular and precise, or stable across time. Clinical information description and coding are performed by physicians and coders with different backgrounds and education. Understanding any risk estimate therefore requires an understanding of the data, and the coding and reporting on which they were based. Factors included and not included, their definitions, the accuracy and completeness of recorded clinical observations, and the faithfulness of their abstraction determine the reliability of the calculations. One solution is to develop ever-more elaborate multivariable risk scoring systems. We illustrate such a system in part 1 of this commentary.

However, it is easy to get lost in the precision of a numeric estimate of expected mortality. Surgeons need to be able to explain to patients and families how the cardiac disease, planned operation, and other factors like physical strength or frailty, disabilities, and comorbidities add up to vulnerability and risk. A simplified approach will improve our understanding of this complicated interplay, and its constant change and development. Congenital heart surgeons have developed the Aristotle Complexity score ${ }^{8}$ and the Risk Adjustment for Congenital Heart Surgery (RACHS)- 1 score, ${ }^{9}$ both of which take into account operative complexity and expert opinion. In part 2 of this commentary, we present a simplified approach similar to these and the Charlson Comorbidity Index to describe patient and surgical complexity.

\section{DESCRIPTION}

Complexity was evaluated and analyzed in all patients undergoing cardiac surgery at the Cleveland Clinic from 1967 to 2010. Patients were divided into 2 cohorts: an evolution cohort including 111,390 patients from 1967 to 2007 and a contemporary risk cohort including 10,337 patients from 2007 to 2010.

\section{Patient Complexity}

We defined patient complexity by comorbid disease components, excluding details related to the cardiac pathology that determined the operation. Patient comorbidities in this context included demographics, functional limitation according to symptoms and clinical acuity, and general cardiac 


\section{Abbreviations and Acronyms \\ aorta $=$ aortic root, ascending aorta, or arch replacement \\ $\mathrm{AV}=$ aortic valve surgery \\ $\mathrm{CABG}=$ coronary artery bypass grafting \\ $\mathrm{MV}=$ mitral valve surgery \\ RACHS $=$ Risk Adjustment for Congenital Heart Surgery}

and noncardiac comorbidities known to limit survival. A list of components used for the elaborate approach (part 1) is presented in Appendix E1, and the comparison of evolution and contemporary risk cohorts in Table 1 . For the simplified approach (part 2), we used the strategy exemplified by the Charlson Comorbidity Index,${ }^{10}$ with inclusion of comorbidities related to each physiologic system and complexity defined by count of comorbid disease components.

\section{Surgical Complexity}

Similar to patient complexity, surgical complexity was assessed by surgical components. All procedural

TABLE 1. Patient characteristics in evolution $(1967-2007 ; n=111,390)$ and contemporary risk $(2007-2010 ; n=10,337)$ cohorts

\begin{tabular}{|c|c|c|c|c|}
\hline \multirow[b]{2}{*}{ Characteristic } & \multicolumn{2}{|c|}{ Evolution Cohort } & \multicolumn{2}{|c|}{ Contemporary Risk Cohort } \\
\hline & $\mathbf{n}^{*}$ & No. $(\%)$ or mean \pm SD & n* & No. $(\%)$ or mean \pm SD \\
\hline \multicolumn{5}{|l|}{ Demography } \\
\hline Age, y & 111,390 & $60 \pm 12$ & 10,337 & $63 \pm 14$ \\
\hline Age $>75$ y $\dagger$ & 111,390 & $11,678(10)$ & 10,337 & $2130(21)$ \\
\hline Male & 111,390 & $83,246(75)$ & 10,337 & $6804(66)$ \\
\hline $\mathrm{BMI}, \mathrm{kg} \cdot \mathrm{m}^{-2}$ & 80,291 & $27 \pm 5.0$ & 10,337 & $29 \pm 8.8$ \\
\hline BMI $>30 \mathrm{~kg} \cdot \mathrm{m}^{-2}$ or $<18.5 \mathrm{~kg} \cdot \mathrm{m}^{-2} \dagger$ & 80,291 & $20,338(25)$ & 10,337 & $3423(33)$ \\
\hline \multicolumn{5}{|l|}{ Acuity } \\
\hline Preoperative NYHA class & 111,322 & & 8908 & \\
\hline I & & $19,670(18)$ & & $2344(26)$ \\
\hline II & & $44,692(40)$ & & $3714(42)$ \\
\hline III & & $17,553(16)$ & & $2320(26)$ \\
\hline IV & & $29,407(26)$ & & $530(6.0)$ \\
\hline Emergency operation & 107,141 & $3194(3.0)$ & 10,329 & $260(2.5)$ \\
\hline Patient acuity $\dagger, \ddagger$ & - & - & 10,337 & $1047(10)$ \\
\hline \multicolumn{5}{|l|}{ Cardiac comorbidity } \\
\hline Previous or evolving MI $\dagger$ & 111,118 & $51,900(47)$ & 10,337 & $2448(24)$ \\
\hline Ejection fraction $<50 \% \dagger$ & 51,738 & $20,579(40)$ & 10,337 & $2788(27)$ \\
\hline Preoperative AF/flutter & 111,390 & $8186(7.3)$ & 9828 & $1123(11)$ \\
\hline Preoperative arrhythmia $\dagger, \S$ & - & - & 10,337 & $2,939(28)$ \\
\hline Heart failure $\dagger$ & 111,390 & $26,416(24)$ & 10,337 & $2510(24)$ \\
\hline Previous cardiac operation $\dagger$ & 111,390 & $19,296(17)$ & 10,337 & $2572(25)$ \\
\hline \multicolumn{5}{|l|}{ Noncardiac comorbidity } \\
\hline History of pharmacologically treated diabetes $\dagger$ & 103,764 & $16,642(16)$ & 10,337 & $2497(24)$ \\
\hline History of PAD $\dagger$ & 61,675 & $25,056(41)$ & 10,337 & $812(7.9)$ \\
\hline History of hypertension $\dagger$ & 82,092 & $50,031(61)$ & 10,337 & $7221(70)$ \\
\hline History of COPD $\dagger$ & 55,865 & $10,654(19)$ & 10,319 & $1293(13)$ \\
\hline History of malignancy $\dagger$ & 80,774 & $4881(6.0)$ & 10,337 & $315(3.0)$ \\
\hline Renal failure $\dagger, \|$ & - & - & 10,337 & $314(3.0)$ \\
\hline History of renal disease 9 & 55,699 & $3,098(5.8)$ & - & - \\
\hline Dyslipidemia $\nmid, * *$ & - & - & 10,337 & $7120(69)$ \\
\hline Cholesterol, mg/dL & 76,968 & $218 \pm 57$ & 8616 & $169 \pm 45$ \\
\hline Bilirubin, mg/dL $\dagger \dagger$ & 55,159 & $0.4,0.6,1.1$ & 10,157 & $0.3,0.5,0.9$ \\
\hline Liver dysfunction $\dagger, \ddagger \dagger$ & 55,159 & $9188(17)$ & 10,157 & $1288(13)$ \\
\hline Hematocrit, $\%$ & 48,350 & $39 \pm 5.5$ & 10,330 & $40 \pm 5.6$ \\
\hline Anemia $\dagger, \S \S$ & 48,350 & $9869(20)$ & 10,330 & $2119(20)$ \\
\hline Previous stroke $\dagger$ & 111,390 & $6710(6.0)$ & 10,337 & $1804(17)$ \\
\hline
\end{tabular}

$S D$, Standard deviation; $B M I$, body mass index; $N Y H A$, New York Heart Association; $M I$, myocardial infarction; $A F$, atrial fibrillation; $P A D$, peripheral arterial disease; $C O P D$, chronic obstructive pulmonary disease. *Number of patients with data available. Because the database dates back to the early 1970s, variables were added periodically, particularly in response to refinements of the Society of Thoracic Surgeons National Database. Thus, missing data were generally "block missing." †Comorbidities incorporated in count of patient complexity. †Preoperative intra-aortic balloon pump support, inotrope support, cardiogenic shock, or emergency operation. §Preoperative atrial or ventricular arrhythmia or heart block. ||Preoperative dialysis or creatinine $\geq 2.5 \mathrm{mg} / \mathrm{dL}^{1}$. \Documentation of renal failure, renal artery stenosis, end-stage renal disease, chronic renal insufficiency, or creatinine $\geq 2 \mathrm{mg} / \mathrm{dL}$. **Total cholesterol $>200 \mathrm{mg} / \mathrm{dL}$, low-density lipoprotein $\geq 130 \mathrm{mg} / \mathrm{dL}$, or high-density lipoprotein $<40 \mathrm{mg} / \mathrm{dL}$. $\dagger \dagger$ Fifteenth, 50 th, and

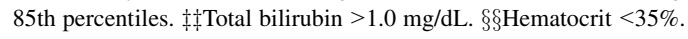


TABLE 2. Evolution cohort (1967-2007): Mutually exclusive surgical groups and associated mortality

\begin{tabular}{|c|c|c|}
\hline Surgical groups & $\mathbf{n}$ & $\begin{array}{c}\text { Hospital mortality, } \\
\text { No. }(\%)\end{array}$ \\
\hline \multicolumn{3}{|l|}{ One component } \\
\hline CABG & 68,626 & $1200(1.7)$ \\
\hline Major LV procedure & 522 & $44(8.4)$ \\
\hline AV & 6864 & $182(2.7)$ \\
\hline Septal myectomy & 578 & $6(1.0)$ \\
\hline MV & 8728 & $190(2.2)$ \\
\hline $\mathrm{AF}$ & 130 & $0(0)$ \\
\hline TV & 212 & $18(7.8)$ \\
\hline Aorta & 445 & $53(12)$ \\
\hline Heart transplant & 1049 & $57(5.4)$ \\
\hline Pericardectomy & 325 & $16(4.9)$ \\
\hline Resection of cardiac tumor & 145 & $8(5.5)$ \\
\hline \multicolumn{3}{|l|}{ Two components } \\
\hline CABG + CEA & 1647 & $84(5.1)$ \\
\hline $\mathrm{CABG}+\mathrm{TMR}$ & 153 & $2(1.3)$ \\
\hline $\mathrm{CABG}+\mathrm{ASD} / \mathrm{PFO}$ & 140 & $2(1.4)$ \\
\hline Major LV procedure + CABG & 1095 & $86(7.8)$ \\
\hline Major LV procedure + MV & 68 & $4(5.6)$ \\
\hline $\mathrm{AV}+\mathrm{ASD} / \mathrm{PFO}$ & 65 & $0(0)$ \\
\hline $\mathrm{AV}+\mathrm{CABG}$ & 4843 & $191(3.9)$ \\
\hline $\mathrm{AV}+\mathrm{MV}$ & 1795 & $94(5.2)$ \\
\hline $\mathrm{AV}+\mathrm{TV}$ & 108 & $6(5.6)$ \\
\hline Septal myectomy + AV & 84 & $4(4.8)$ \\
\hline Septal myectomy + MV & 152 & $5(3.3)$ \\
\hline Septal myectomy + CABG & 175 & $4(2.3)$ \\
\hline $\mathrm{MV}+\mathrm{CABG}$ & 3619 & $219(6.1)$ \\
\hline $\mathrm{MV}+\mathrm{TV}$ & 1202 & $60(5.0)$ \\
\hline $\mathrm{MV}+\mathrm{ASD} / \mathrm{PFO}$ & 251 & $7(2.8)$ \\
\hline $\mathrm{AF}+\mathrm{MV}$ & 251 & $2(0.8)$ \\
\hline $\mathrm{TV}+\mathrm{CABG}$ & 68 & $6(8.8)$ \\
\hline Aorta + CABG & 327 & $40(12.2)$ \\
\hline Aorta + AV & 2179 & $52(2.4)$ \\
\hline \multicolumn{3}{|l|}{ Three components } \\
\hline Major LV procedure $+\mathrm{MV}+\mathrm{CABG}$ & 164 & $16(9.8)$ \\
\hline $\mathrm{AV}+\mathrm{CABG}+\mathrm{CEA}$ & 57 & $5(8.8)$ \\
\hline $\mathrm{AV}+\mathrm{MV}+\mathrm{CABG}$ & 917 & $66(7.2)$ \\
\hline $\mathrm{AV}+\mathrm{MV}+\mathrm{TV}$ & 412 & $40(9.7)$ \\
\hline $\mathrm{AV}+\mathrm{MV}+\mathrm{TV}+\mathrm{CABG}$ & 209 & $26(12)$ \\
\hline Septal myectomy + AV + CABG & 55 & $3(5.5)$ \\
\hline $\mathrm{MV}+\mathrm{CABG}+\mathrm{ASD} / \mathrm{PFO}$ & 124 & $5(4.0)$ \\
\hline $\mathrm{MV}+\mathrm{TV}+\mathrm{ASD} / \mathrm{PFO}$ & 70 & $1(1.4)$ \\
\hline $\mathrm{MV}+\mathrm{TV}+\mathrm{CABG}$ & 461 & $43(9.3)$ \\
\hline $\mathrm{AF}+\mathrm{MV}+\mathrm{CABG}$ & 66 & $1(1.5)$ \\
\hline $\mathrm{AF}+\mathrm{MV}+\mathrm{TV}$ & 94 & $2(2.1)$ \\
\hline Aorta + AV + CABG & 1062 & $80(7.5)$ \\
\hline Aorta + AV + MV & 180 & $16(8.9)$ \\
\hline Aorta + MV + CABG & 36 & $8(22)$ \\
\hline
\end{tabular}

components of the 111,390 heart operations performed in adults at the Cleveland Clinic from 1967 to 2007 were tabulated. Stand-alone components were those often performed as an isolated operation. Add-on components were
TABLE 2. Continued

\begin{tabular}{|c|c|c|}
\hline Surgical groups & $\mathbf{n}$ & $\begin{array}{c}\text { Hospital mortality, } \\
\text { No. }(\%)\end{array}$ \\
\hline \multicolumn{3}{|l|}{ Four components } \\
\hline Aorta $+\mathrm{AV}+\mathrm{MV}+\mathrm{CABG}$ & 141 & $9(6.4)$ \\
\hline Aorta $+\mathrm{AV}+\mathrm{MV}+\mathrm{TV}$ & 38 & $7(18)$ \\
\hline Miscellaneous & 1425 & $76(5.3)$ \\
\hline \multicolumn{3}{|c|}{$\begin{array}{l}C A B G \text {, Coronary artery bypass grafting; } L V \text {, left ventricle; } A F, \text { Maze procedure } \\
\text { (including non-cut-and-sew Maze); } C E A \text {, carotid endarterectomy; } T M R \text {, transmyo- } \\
\text { cardial (laser) revascularization; } A S D / P F O \text {, atrial septal defect or patent foramen } \\
\text { ovale closure; } M V \text {, mitral valve surgery; } A V \text {, aortic valve surgery; } T V \text {, tricuspid valve } \\
\text { surgery; Aorta, aortic root, ascending aorta, or arch replacement. }\end{array}$} \\
\hline
\end{tabular}

those not commonly performed as an isolated operation. Ignored components were minor portions of an operation and were not counted.

Eleven components were considered stand-alone:

- $\mathrm{CABG}$

- $\mathrm{AV}$

- MV

- Tricuspid valve surgery (TV)

- Maze procedure, including non-cut-and-sew maze (AF)

- Aortic root, ascending aorta, or arch replacement (aorta)

- Major left ventricular procedure

- Septal myectomy

- Resection of cardiac tumor

- Pericardectomy

- Heart transplant

Three components were considered add-on:

- Carotid endarterectomy

- Transmyocardial (laser) revascularization

- Atrial septal defect or patent foramen ovale closure

Ignored minor components included pacemaker or lead procedures, myocardial biopsy, coronary reimplantation, reimplantation of coronary graft, aortoplasty, aortic endarterectomy, aortic biopsy, aortic thrombectomy, femoral artery repair, left atrial appendage amputation or closure, pericardial procedure other than pericardectomy, minor ventriculotomy, and cell transplant.

For the elaborate approach, every combination of these surgical components in the evolution cohort, for which there were at least 50 patients or 5 events (47 mutually exclusive surgical groups, isolated or combinations) was analyzed (Table 2). For the simplified approach, surgical complexity was defined by number of distinct stand-alone and add-on components comprising a given operation.

\section{Evolution of Complexity}

Patient comorbidity factors such as age, body mass index, and proportions of female patients and patients with diabetes mellitus have increased across time, whereas New York Heart Association functional class has decreased, indicating 

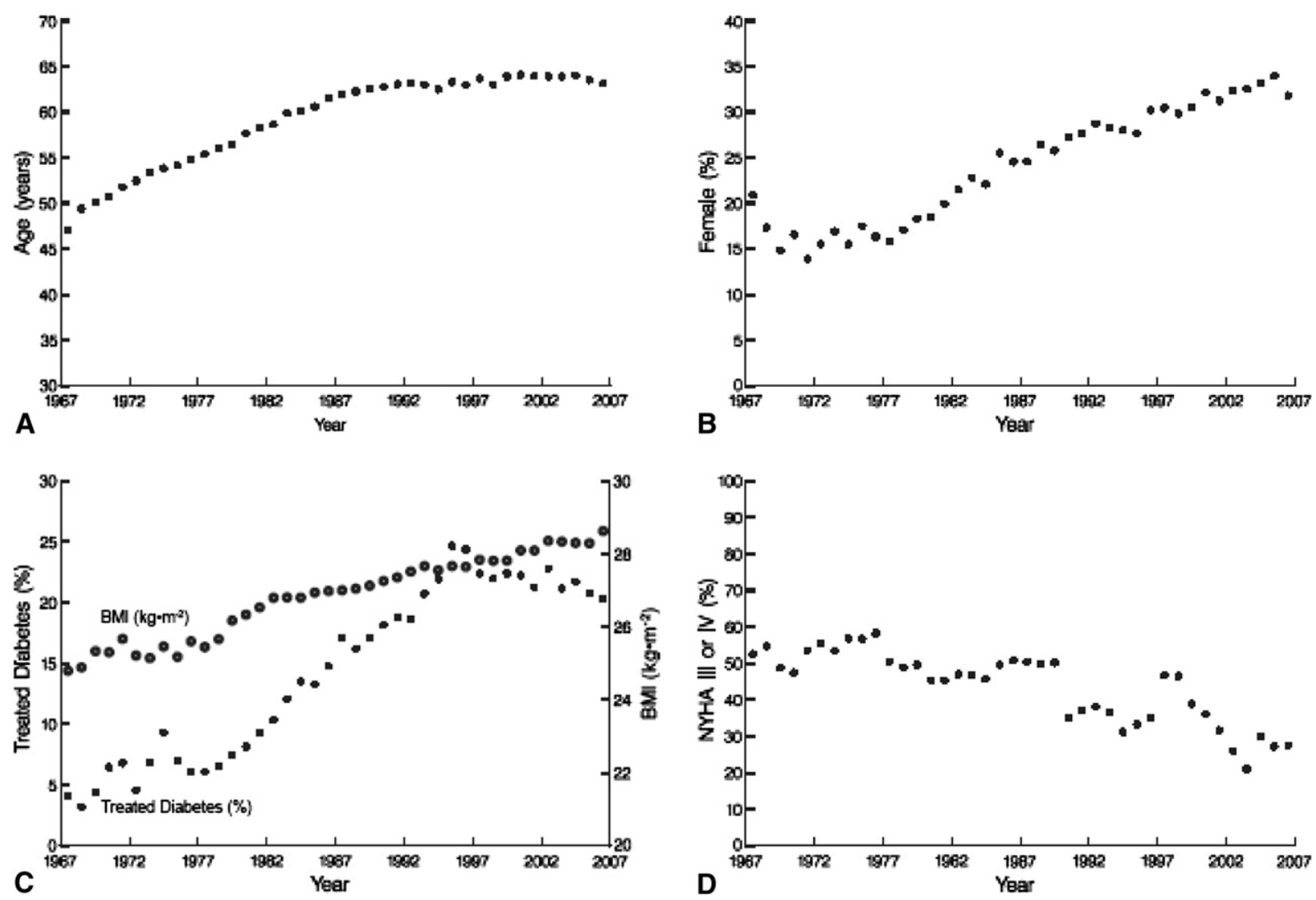

FIGURE 1. Evolution of patient complexity. Each circle represents a 1-year average (mean for continuous variables and percentage for categorical variables). A, Age. B, Female gender. C, Treated diabetes mellitus and body mass index (BMI). D, Patients in New York Heart Association (NYHA) functional classes III and IV.

that in recent time more complex patients were operated on earlier in the course of their heart disease (Table 1 and Figure 1).

Surgical complexity increased across time, accelerating since the mid 1990s (Figure 2, A). The proportion of isolated $\mathrm{CABG}$ procedures steadily declined across time, whereas $C A B G$ combined with other procedures increased (Figure 2,B). Thus, the proportion of operations for which benchmarks have been developed by the Society of Thoracic Surgeons and included in Society of Thoracic Surgeons scores has declined such that more than half the operations performed at our institution are now more complex than these, and no benchmarks for risk are available (Figure 2,C).

In the contemporary risk cohort, $49 \%$ of operations performed were 1 component; $33 \%, 2$ component; $13 \%, 3$ component; and $4 \%, \geq 4$ component. Coronary artery bypass grafting was performed in 86 different combinations, including isolated CABG, 13 combinations of $\mathrm{CABG}+1$ component, 28 combinations of $\mathrm{CABG}+2$ components, 31 combinations of $\mathrm{CABG}+3$ components, 11 combinations of $\mathrm{CABG}+4$ components, and 2 combinations of CABG +5 components (Box 1). An aortic valve procedure (AV) was performed in 85 different combinations, including an isolated $\mathrm{AV}, 10$ combinations of $\mathrm{AV}+1$ component, 26 combinations of $\mathrm{AV}+2$ components, 31 combinations of $\mathrm{AV}+3$ components, 15 combinations of $\mathrm{AV}+4$ components, and 2 combinations of $\mathrm{AV}+5$ components (Box E1). A mitral valve procedure (MV) was performed in 83 different combinations, including an isolated MV, 11 combinations of MV +1 component, 25 combinations of MV +2 components, 31 combinations of $\mathrm{MV}+3$ components, 13 combinations of $\mathrm{MV}+4$ components, and 2 combinations of $\mathrm{MV}+5$ components (Box E2). An aortic procedure was performed in 66 different combinations, including an isolated aortic procedure, 9 combinations of aortic procedure +1 component, 21 combinations of aortic procedure +2 components, 22 combinations of aortic procedure +3 components, 11 combinations of aortic procedure +4 components, and 2 combinations of aortic procedure +5 components (Box E3).

\section{PART 1: ELABORATE MULTIVARIABLE APPROACH TO RISK ASSESSMENT}

Risk factors for hospital mortality were identified and analyzed separately for patient comorbidity components and surgical components using logistic regression analysis. 

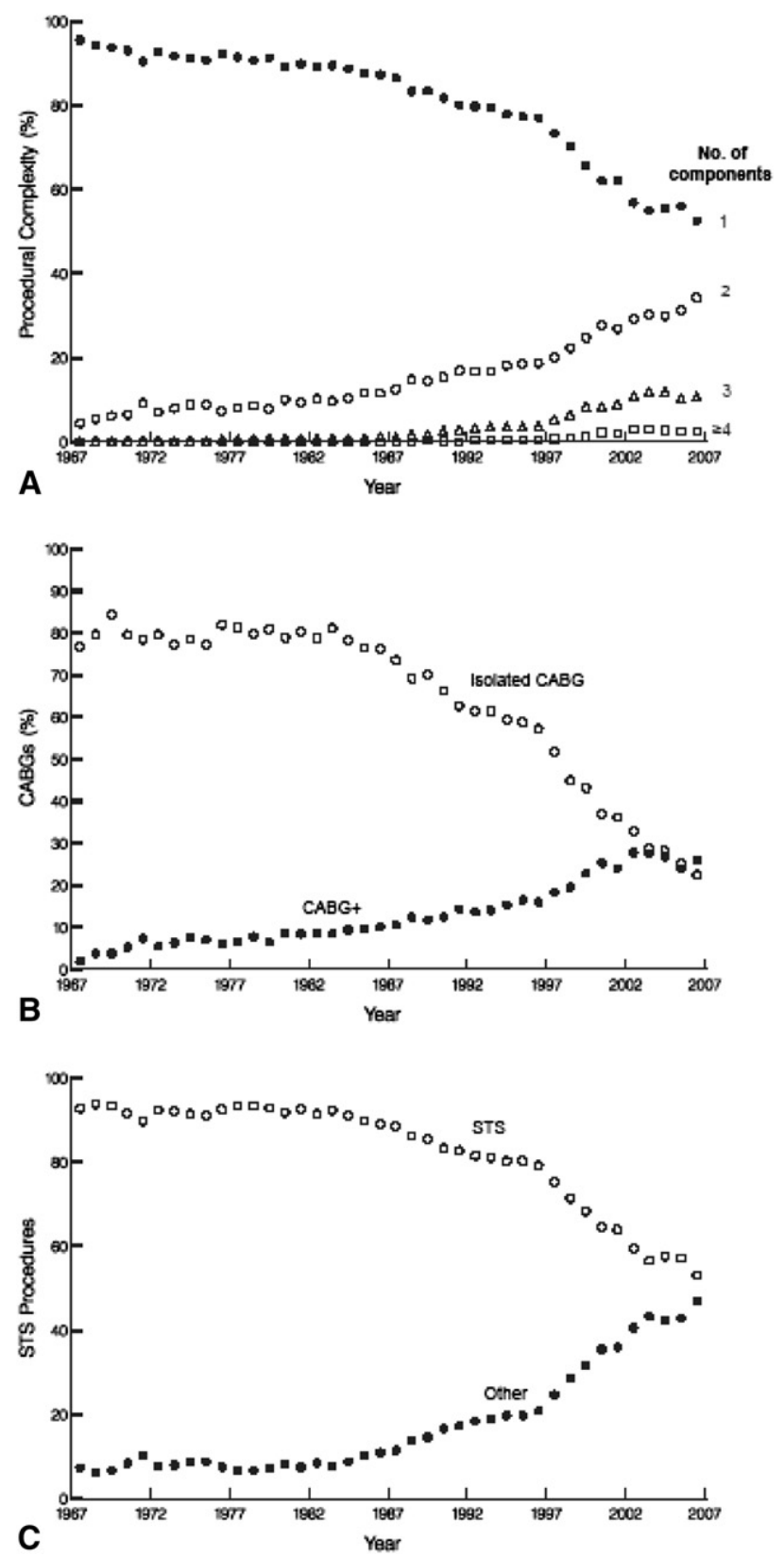

FIGURE 2. Evolution of surgical complexity. A, Surgical complexity illustrated as percentage of patients undergoing operations with 1 (filled circles), 2 (open circles), 3 (triangles), or $\geq 4$ (squares) components. $\mathrm{B}$, Percentage of patients undergoing isolated coronary artery bypass grafting $(C A B G)$ or $\mathrm{CABG}$ plus other components $(\mathrm{CABG}+)$. $\mathrm{C}$, Percentage of patients undergoing procedures for which risk adjustment equations have been developed by the Society of Thoracic Surgeons (STS) and those more complex than these (Other).

In total, 3046 hospital deaths occurred $(2.7 \%)$ over 40 years from 1967 to 2007 . Hospital mortality decreased substantially across time (Figure 3 ). Patient complexity alone was a powerful predictor of hospital mortality $(\mathrm{C}=0.812$; Figure 4, Table E1). This analysis was used to calculate a patient complexity score.

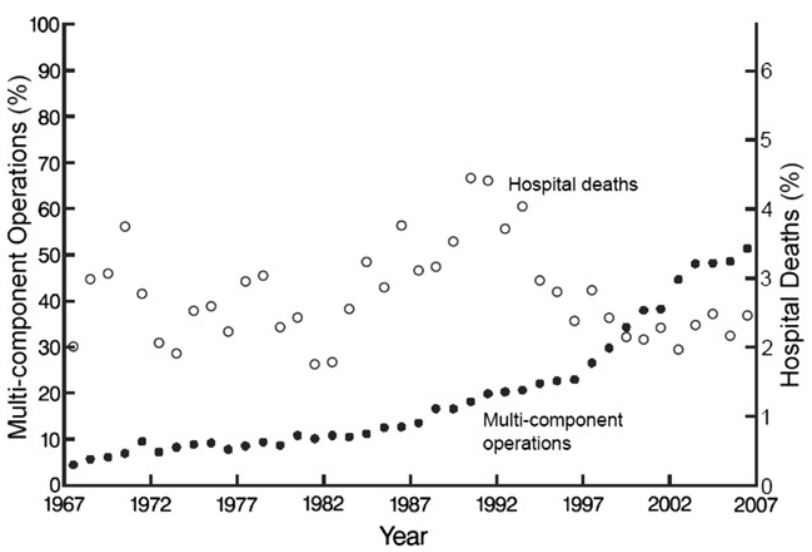

FIGURE 3. Prevalence of multicomponent operations ( $\geq 2$ components, filled circles) and percent hospital mortality (open circles).

Next, the association between hospital mortality and surgical complexity was assessed by logistic regression analysis in 3 models: (1) the operation accounted for by individual surgical components, (2) the operation accounted for by surgical groups as defined in Table 2, and (3) the operation accounted for by individual surgical components combined with statistically significant groups (interactions) (Figure 5).

The $\mathrm{C}$ statistic for the unadjusted model containing the individual surgical components was only 0.647 , but it was 0.824 after adjusting for patient complexity score (Figure 4 and Table E2). When using surgical groups instead of individual surgical components to calculate the contribution of the operation to risk, the $\mathrm{C}$ statistic for the unadjusted group model was 0.652 and was 0.827 after adjusting for patient complexity score. Certain surgical groups were poorly accounted for by components alone, as illustrated by outliers in Figure 5, indicating that important interactions existed. Aorta procedures with concomitant CABG, isolated TV, isolated aorta, major left ventricular procedure, and $\mathrm{CABG}$

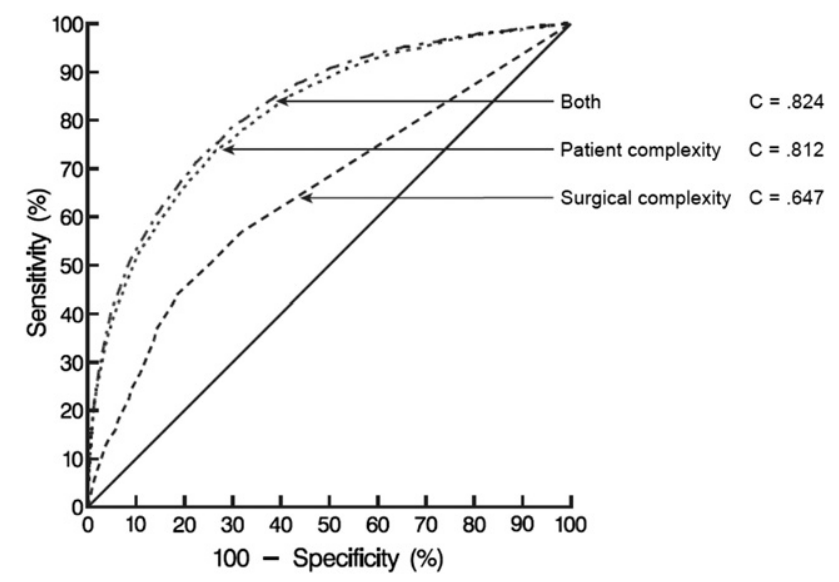

FIGURE 4. Receiver-operator curves for logistic regression analysis of patient (short-dash line) and surgical complexity (long-dash line). 


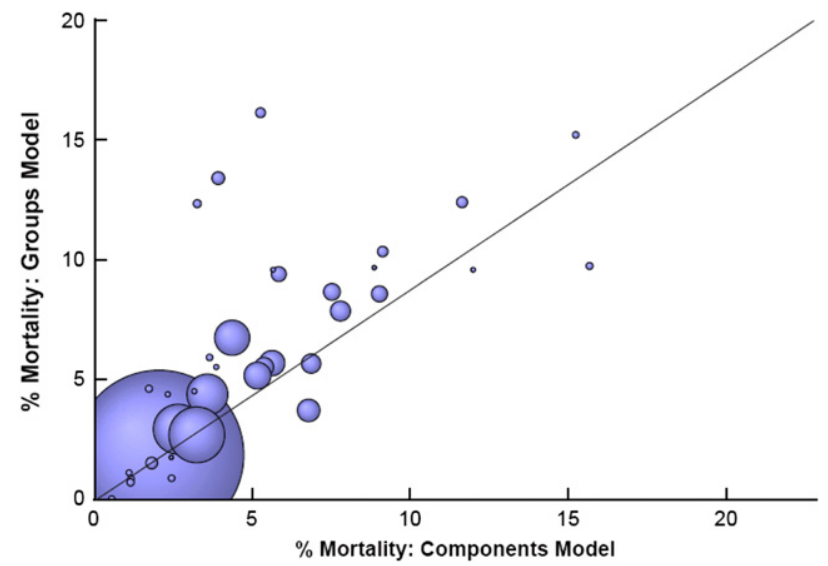

FIGURE 5. Bubble plot of predicted risk of hospital mortality calculated by isolated surgical components versus surgical groups. Bubbles distant from line of identity (outliers) represent important interactions. The size of each bubble represents size of the surgical group, with the largest being isolated coronary artery bypass grafting.

with concomitant MV were associated with higher or lower risk. In the final model, interactions were accounted for by combining components and statistically significant groups to modulate risk, resulting in a $\mathrm{C}$ statistic of 0.694 , and 0.827 after adjusting for patient complexity score (Table 3). In all 3 models, patient, rather than surgical, complexity

TABLE 3. Logistic model for hospital death incorporating surgical components and interactions

\begin{tabular}{lcc}
\hline \multicolumn{1}{c}{ Procedure } & Estimate \pm SE & $\boldsymbol{P}$ \\
\hline Pericardiectomy & $1.32 \pm 0.22$ & $<.0001$ \\
Major LV procedure & $1.07 \pm 0.11$ & $<.0001$ \\
Atrial myxoma & $0.93 \pm 0.33$ & .004 \\
Carotid endarterectomy & $0.92 \pm 0.11$ & $<.0001$ \\
Septal myectomy & $0.66 \pm 0.20$ & .001 \\
Aorta & $0.55 \pm 0.088$ & $<.0001$ \\
AV & $0.36 \pm 0.053$ & $<.0001$ \\
MV & $0.35 \pm 0.065$ & $<.0001$ \\
CABG & $0.33 \pm 0.059$ & $<.0001$ \\
Maze procedure & $0.20 \pm 0.17$ & .2 \\
TV & $0.16 \pm 0.089$ & .07 \\
Transplant & $0.093 \pm 0.16$ & .6 \\
Transmyocardial revascularization & $-0.092 \pm 0.60$ & .8 \\
Atrial septal defect or patent foramen & $0.15 \pm 0.21$ & .4 \\
$\quad$ ovale closure & & \\
Interactions & & \\
$\quad$ CABG + aorta & $1.20 \pm 0.21$ & $<.0001$ \\
Isolated aorta & $1.04 \pm 0.19$ & $<.0001$ \\
Isolated TV & $0.88 \pm 0.29$ & .002 \\
Isolated major LV procedure & $0.48 \pm 0.21$ & .05 \\
CABG + MV & $0.35 \pm 0.11$ & .0005 \\
Preoperative risk & $0.96 \pm 0.016$ & $<.0001$ \\
Intercept & $-0.70 \pm 0.08$ & $<.0001$ \\
\hline C $-0.83 . S E$, Stat & & \\
\hline
\end{tabular}

$\mathrm{C}=0.83 . S E$, Standard error; $L V$, left ventricle; aorta, aortic root, ascending aorta, or arch replacement; $A V$, aortic valve surgery; $M V$, mitral valve surgery; $C A B G$, coronary artery bypass grafting; $T V$, tricuspid valve surgery. accounted for most of the information predicting hospital mortality (Figure 4).

The elaborate approach based on multivariable analysis is of great value for risk-adjusted national reporting of outcomes and quality improvement efforts. It is patient and risk factor specific, allowing the best possible direct comparison of treatment options and program outcomes. Developing such a score has allowed us to better understand issues related to risk scoring. Its limitations are its complexity, which is why only 1 - and 2-component operations are covered by scores based on this approach. Practical implementation of an elaborate score, including even more granular data, requires a large data set with many variables solved automatically from entry into electronic medical records. It also requires constant updates as we learn and progress (Figure 6).

\section{PART 2: SIMPLIFIED APPROACH TO CONTEMPORARY RISK ASSESSMENT}

The simplified approach defined patient complexity by count of comorbid disease components (Table 1) and defined surgical complexity by count of surgical components. For the 10,337 patients undergoing cardiac operations performed from 2007 to $2010,4191(40 \%)$ had $\geq 5$ comorbidities (Figure 7). Postoperative mortality and morbidity increased, and late survival decreased with increasing patient (Table 4 and Figure $8, A$ ) and surgical complexity (Table 5 and Figure $8, B)$. As patient complexity increased, the risk of multicomponent procedures became more evident (Figure 9). However, even for patients with many comorbidities, complex operations were performed with relatively low risk and acceptable survival. The relationship of surgical complexity and hospital mortality varied somewhat according to type of procedure (Figure 10), with particular variability for thoracic aorta procedures. Intermediate-term survival decreased incrementally as patient and surgical complexity increased (Figure 11, $A$ and $B$ ).

Discussions with patients and families about risk of complex operations are not only about providing percentages, but also about conveying an understanding of the relationship between patient factors, comorbidities, operative components, and outcomes. This is not easy to do, particularly for the complex patient about to undergo a complex operation. This is the primary advantage of a simple tool to illustrate the interplay of these factors. Patients undergoing simple operations tended to have few comorbidities; patients requiring more complex operations always had several comorbidities (Figure 12).

The list of patient factors related to risk will continue to evolve. For example, recent discussions about patient frailty are an indication that we have not captured all deciding factors. ${ }^{11-14}$ Included operations and their components were also limited; we are aware of the possibility of further dividing these operations and components into subgroups, 

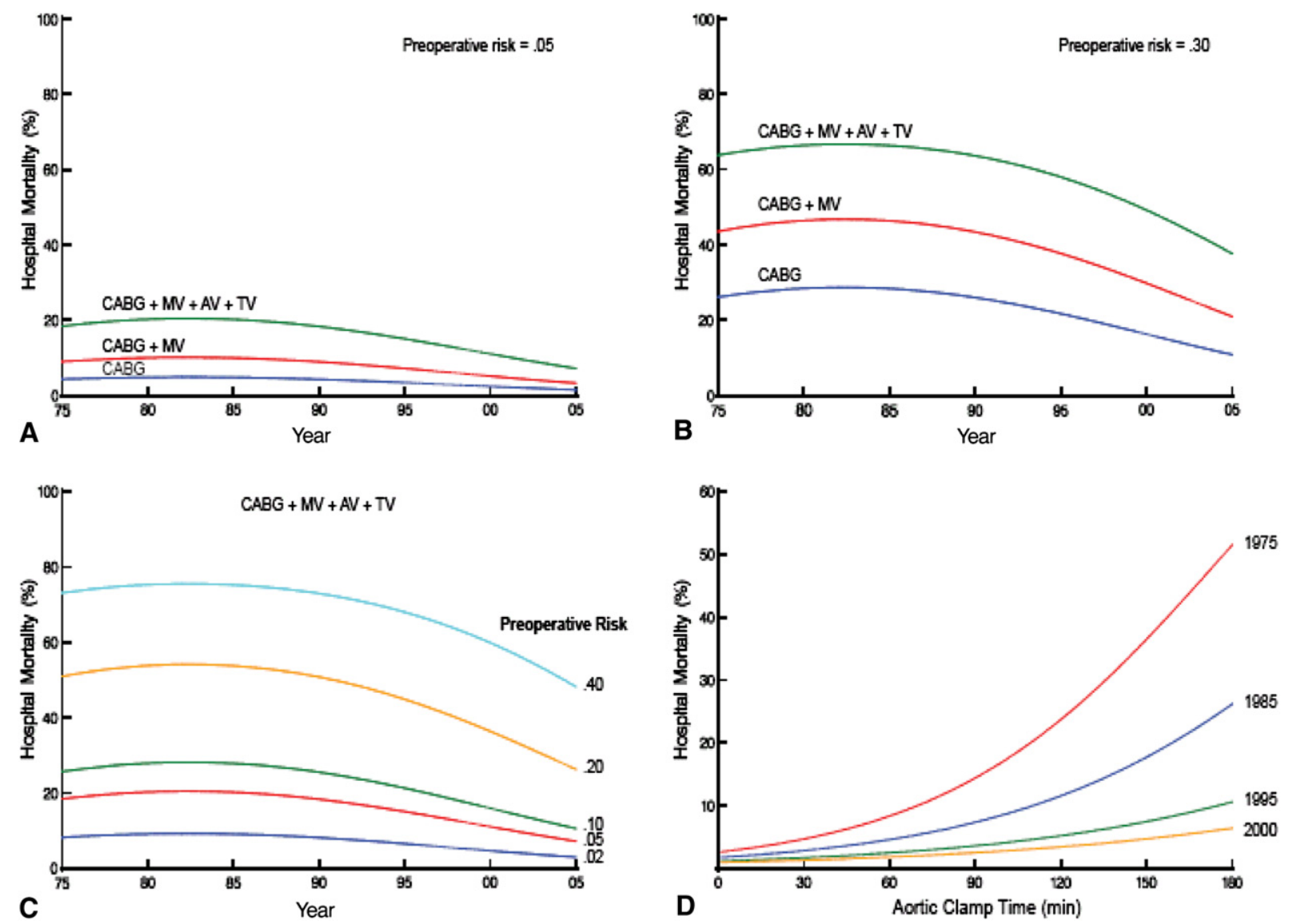

FIGURE 6. Predicted decline in hospital mortality for different patient risk profiles. A, For a fixed preoperative patient risk profile of 0.05 , predicted mortality for 1-, 2-, and 4-component operations. B, For a preoperative patient risk profile of 0.30, predicted mortality for 1-, 2-, and 4-component operations. C, For a range of preoperative patient risk profiles, mortality for a 4-component operation. D, Univariable effect of aortic clamp time for 4 eras. $C A B G$, Coronary artery bypass grafting; $M V$, mitral valve surgery; $A V$, aortic valve surgery; $T V$, tricuspid valve surgery.

such as valve repair versus replacement, pathology, access, and technology. Counting operative components suggests that risk of each component is the same. Traditional

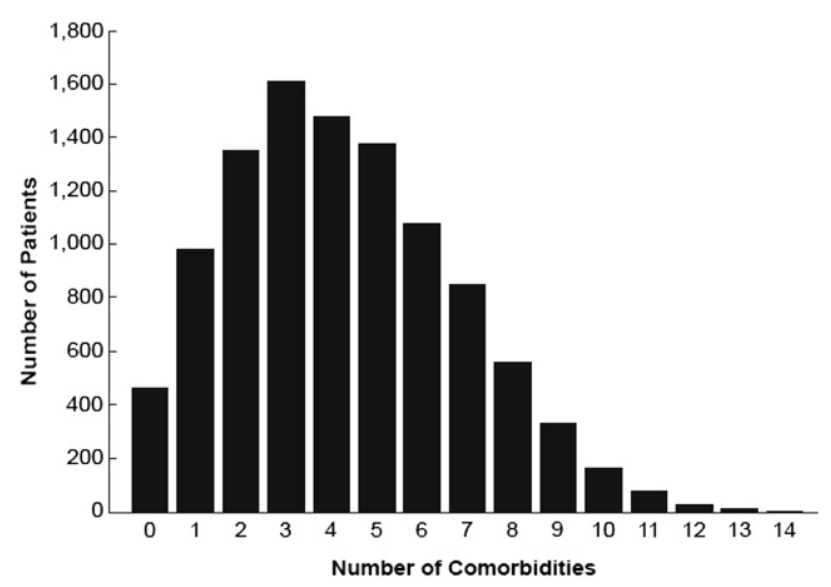

FIGURE 7. Contemporary complexity: Distribution of patient comorbidities. models presume that variations in the operating room are absorbed by patient factors included in the model when, in fact, the same operation varies according to the pathology and etiology for which it is performed. Operative and cardiopulmonary bypass times are likely to influence risk, as can other factors related to surgeon skill and experience.

Some variables do not fall neatly into patient or surgical factors because they carry information about both. Among these is surgical acuity, which reflects not only serious, possibly life-threatening, patient risk, but also interruptions in the surgical schedule, operations performed off hours with less experienced personnel, and fatigue. Other variables that span both categories are cardiac comorbidities, such as extent of coronary disease, endocarditis, previous cardiac surgery, and atrial fibrillation. These reflect a patient's condition, but also influence the surgical approach, which is tailored to the patient's anatomy and pathology, and may vary among surgeons. The surgeon may decide to address or not to address cardiac pathologies such as moderate valve and coronary lesions, and atrial fibrillation. We did not consider the severity of the cardiac 
TABLE 4. Contemporary risk cohort (2007-2010): Postoperative mortality and morbidity complications by number of patient comorbidities

\begin{tabular}{|c|c|c|c|c|c|c|c|c|}
\hline \multirow[b]{2}{*}{ Complications } & \multicolumn{7}{|c|}{ Comorbidities } & \multirow[b]{2}{*}{$P^{*}$} \\
\hline & $\begin{array}{c}\text { None } \\
(\mathrm{n}=461) \\
\text { No. }(\%)\end{array}$ & $\begin{array}{c}1 \\
(\mathrm{n}=978) \\
\text { No. }(\%)\end{array}$ & $\begin{array}{c}2 \\
(n=1348) \\
\text { No. }(\%)\end{array}$ & $\begin{array}{c}3-4 \\
(\mathrm{n}=\mathbf{3 0 8 6}) \\
\text { No. }(\%)\end{array}$ & $\begin{array}{c}5-6 \\
(\mathrm{n}=\mathbf{2 4 5 1}) \\
\text { No. }(\%)\end{array}$ & $\begin{array}{c}7-8 \\
(\mathrm{n}=1404) \\
\text { No. }(\%)\end{array}$ & $\begin{array}{c}\geq 9 \\
(\mathbf{n}=609) \\
\text { No. }(\%)\end{array}$ & \\
\hline \multicolumn{9}{|l|}{ Mortality } \\
\hline In-hospital & $0(0)$ & $3(0.31)$ & $1(0.07)$ & $50(1.6)$ & $79(3.2)$ & $60(4.3)$ & $75(12)$ & $<.0001$ \\
\hline In-hospital or within $30-d$ & $1(0.22)$ & $4(0.41)$ & $3(0.22)$ & $58(1.9)$ & $94(3.8)$ & $76(5.4)$ & $80(13)$ & $<.0001$ \\
\hline 6-Month survival, \% & 99.8 & 99.1 & 98.3 & 96.7 & 92.6 & 88 & 75 & $<.0001$ \\
\hline 12-Month survival, $\%$ & 99.3 & 98.4 & 97.5 & 95.7 & 90.3 & 83 & 70 & \\
\hline \multicolumn{9}{|l|}{ Morbidity } \\
\hline STS composite $\dagger$ & $41(8.9)$ & $87(8.9)$ & $158(12)$ & $568(18)$ & $731(30)$ & $586(42)$ & $335(55)$ & $<.0001$ \\
\hline Renal failure & $4(0.88)$ & $7(0.72)$ & $15(1.1)$ & $128(4.2)$ & $191(8.0)$ & $168(12)$ & $106(18)$ & $<.0001$ \\
\hline Stroke & $7(1.5)$ & $6(0.62)$ & $25(1.9)$ & $44(1.5)$ & $48(2.0)$ & $32(2.4)$ & $19(3.3)$ & .002 \\
\hline Reoperation for bleeding & $21(4.6)$ & $40(4.1)$ & $44(3.3)$ & $119(3.9)$ & $151(6.3)$ & $96(7.1)$ & $67(12)$ & $<.0001$ \\
\hline Prolonged ventilation $(>24 \mathrm{~h})$ & $10(2.2)$ & $42(4.3)$ & $98(7.3)$ & $417(14)$ & $587(25)$ & $466(34)$ & $294(51)$ & $<.0001$ \\
\hline \multicolumn{9}{|c|}{ Length of stay, 15 th, 50 th, and 85 th percentiles } \\
\hline ICU, hours & $21,25,48$ & $21,26,53$ & $22,27,73$ & $22,32,97$ & $24,52,160$ & $27,84,238$ & 44, 106, 477 & $<.0001$ \\
\hline Postoperative, days & $4,5,7$ & $4,5,8$ & $4,6,9$ & $5,7,11$ & $5,8,16$ & $6,11,21$ & $7,13,29$ & $<.0001$ \\
\hline
\end{tabular}

$\overline{S T S}$, Society of Thoracic Surgeons; ICU, intensive care unit. *Test for trend. †Composite event for any of the following STS complications: renal failure, stroke, prolonged ventilation, reoperation for bleeding, graft occlusion, valve dysfunction, or other cardiac reoperation.

pathologies (addressed or not addressed), or success or completeness of the operations. We did not study benefits of surgery relative to other treatment options; however, multiple publications from this institution have demonstrated increasing relative benefit as patients become sicker and higher risk. ${ }^{6,15}$

\section{CONCLUSIONS}

The traditional, elaborate multivariable approach to risk scores has an important place, but even with large national databases and ever richer variables, these scores do not yet apply to complex patients with complex heart disease. The need for a scoring system to benchmark outcomes of complex procedures is obvious. Benchmarking only the simplest procedures does not give credit to institutions making great efforts to care for complex patients requiring complex operations. When facing these patients, we as surgeons use traditional scores developed for simple operations and extrapolate the patient's risk as best we can, guessing at the contribution of factors not covered by these scores. The approach congenital heart surgeons have taken with the Aristotle and RACHS scores is also a compromise; these scores use patient data to calibrate expert opinion about the complexity of the operation.

TABLE 5. Contemporary risk cohort (2007-2010): Postoperative mortality and morbidity complications by number of surgical components

\begin{tabular}{|c|c|c|c|c|c|c|}
\hline \multirow[b]{2}{*}{ Complications } & \multicolumn{5}{|c|}{ Surgical components } & \multirow[b]{2}{*}{$P^{*}$} \\
\hline & $\begin{array}{c}1 \\
(\mathrm{n}=\mathbf{5 1 0 7}) \\
\text { No. }(\%)\end{array}$ & $\begin{array}{c}2 \\
(\mathrm{n}=\mathbf{3 4 6 7}) \\
\text { No. }(\%)\end{array}$ & $\begin{array}{c}\mathbf{3} \\
(\mathrm{n}=\mathbf{1 3 3 5}) \\
\text { No. }(\%) \\
\end{array}$ & $\begin{array}{c}4 \\
(\mathrm{n}=366) \\
\text { No. }(\%)\end{array}$ & $\begin{array}{c}\geq 5 \\
(n=62) \\
\text { No. }(\%)\end{array}$ & \\
\hline \multicolumn{7}{|l|}{ Mortality } \\
\hline In-hospital & $102(2.0)$ & $78(2.3)$ & $53(4.0)$ & $30(8.2)$ & $5(8.1)$ & $<.0001$ \\
\hline In-hospital or $30-\mathrm{d}$ & $119(2.3)$ & $95(2.7)$ & $61(4.6)$ & $34(9.3)$ & $7(11)$ & $<.0001$ \\
\hline 6-Month survival, \% & 95.4 & 94.0 & 91 & 83 & 71 & $<.0001$ \\
\hline 12-Month survival, $\%$ & 93.8 & 92.2 & 89 & 79 & 68 & \\
\hline \multicolumn{7}{|l|}{ Morbidity } \\
\hline STS composite $\dagger$ & $1008(20)$ & $854(25)$ & $457(34)$ & $153(42)$ & $34(55)$ & $<.0001$ \\
\hline Renal failure & $241(4.9)$ & $215(6.3)$ & $105(7.9)$ & $45(12)$ & $13(21)$ & $<.0001$ \\
\hline Stroke & 77 (1.6) & $66(1.9)$ & $29(2.2)$ & $9(2.5)$ & $0(0)$ & .11 \\
\hline Reoperation for bleeding & $200(4.0)$ & $198(5.8)$ & $103(7.8)$ & $31(8.6)$ & $6(9.7)$ & $<.0001$ \\
\hline Prolonged ventilation $(>24 \mathrm{~h})$ & $728(15)$ & $655(19)$ & $375(28)$ & $131(36)$ & $25(41)$ & $<.0001$ \\
\hline \multicolumn{7}{|c|}{ Length of stay, 15 th, 50 th, and 85 th percentiles } \\
\hline ICU, hours & $22,30,105$ & $23,45,140$ & $25,67,182$ & $27,85,333$ & $40,106,509$ & $<.0001$ \\
\hline Postoperative, days & $4,6,12$ & $5,7,14$ & $6,9,18$ & $7,11,23$ & $7,13,29$ & $<.0001$ \\
\hline
\end{tabular}

$S T S$, Society of Thoracic Surgeons; ICU, intensive care unit. *Test for trend. †Composite event for any of the following STS complications: renal failure, stroke, prolonged ventilation, reoperation for bleeding, graft occlusion, valve dysfunction, or other cardiac reoperation. 
Comorbidities $(n=10,337)$

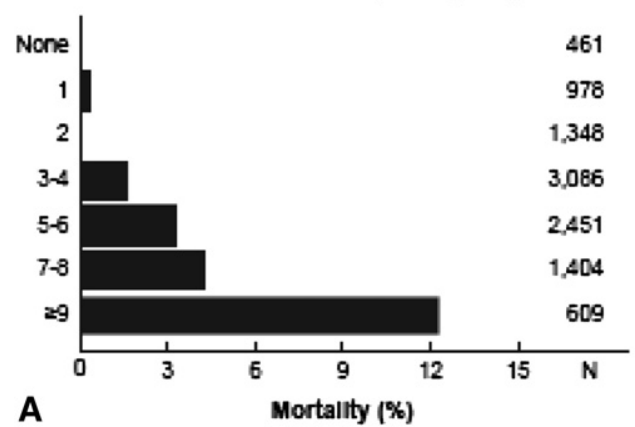

Surgical Components $(n=10,337)$

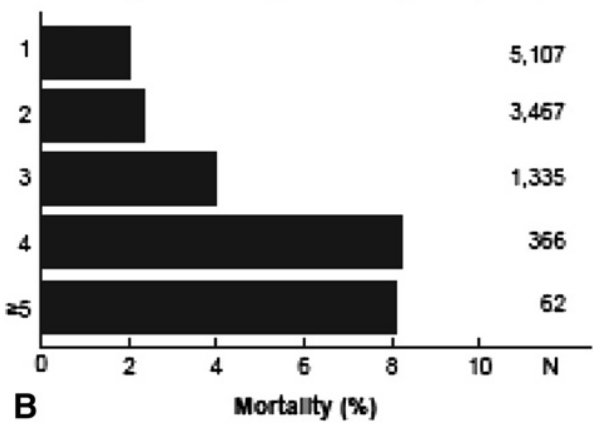

FIGURE 8. Contemporary complexity and hospital mortality. A, Hospital mortality according to number of comorbidities (patient complexity). B, Hospital mortality according to number of surgical components (surgical complexity).

Risk is better understood in the context of evolving patient and procedure complexity than by a single numeric estimate of expected mortality. The interplay of patient and surgical complexity with outcomes and survival after heart operations is best understood by combining conventional elaborate multivariable analysis and a simple approach based on counts of comorbidities and required surgical components. Risk of postoperative mortality and morbidity increases and survival worsens with patient and surgical complexity, with patient complexity being most important. There is a strong correlation between mortality (hospital and 30-day), morbidity, and 6- and 12-month survival.

Today, however, few operations are hopeless. A simplified approach to risk assessment improves our understanding of complexity and outcomes, and facilitates discussions with patients and families.

\section{References}

1. Shahian DM, O’Brien SM, Filardo G, Ferraris VA, Haan CK, Rich JB, et al. The Society of Thoracic Surgeons 2008 cardiac surgery risk models: part 1: coronary artery bypass grafting surgery. Ann Thorac Surg. 2009;88:S2-22.

2. Shahian DM, O'Brien SM, Filardo G, Ferraris VA, Haan CK, Rich JB, et al. The Society of Thoracic Surgeons 2008 cardiac surgery risk models: part 3:

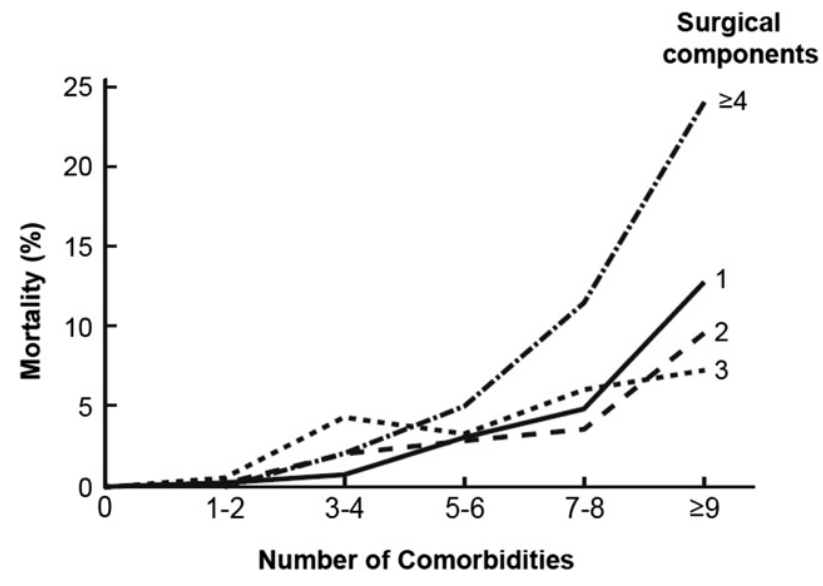

FIGURE 9. Nomogram for hospital mortality according to number of comorbidities for patients undergoing 1-, 2-, 3-, or $\geq 4$-component operations. valve plus coronary artery bypass grafting surgery. Ann Thorac Surg. 2009; 88:S43-62.

3. O'Brien SM, Shahian DM, Filardo G, Ferraris VA, Haan CK, Rich JB, et al. The Society of Thoracic Surgeons 2008 cardiac surgery risk models: part 2: isolated valve surgery. Ann Thorac Surg. 2009;88:S23-42.

4. Kouchoukos NT, Blackstone EH, Doty DB, Hanley FL, Karp RB. Cardiac surgery. Philadelphia: Churchill Livingstone; 2003: 254-350.

5. Kirklin JW, Blackstone EH, Bargeron LM Jr, Pacifico AD, Kirklin JK. The repair of atrioventricular septal defects in infancy. Int J Cardiol. 1986;13:333-60.

6. Bhudia SK, McCarthy PM, Kumpati GS, Helou J, Hoercher KJ, Rajeswaran J, et al. Improved outcomes after aortic valve surgery for chronic aortic regurgitation with severe left ventricular dysfunction. $J$ Am Coll Cardiol. 2007;49: 1465-71.

7. Blackstone EH. Thinking beyond the risk factors. Eur J Cardiothorac Surg. 2006;29:645-52.

8. Lacour-Gayet F, Clarke D, Jacobs J, Gaynor W, Hamilton L, Jacobs M, et al. The Aristotle score for congenital heart surgery. Semin Thorac Cardiovasc Surg Pediatr Card Surg Anпu. 2004;7:185-91.

9. Jenkins KJ. Risk adjustment for congenital heart surgery: the RACHS-1 method. Semin Thorac Cardiovasc Surg Pediatr Card Surg Annu. 2004;7:180-4.

10. Charlson ME, Pompei P, Ales KL, MacKenzie CR. A new method of classifying prognostic comorbidity in longitudinal studies: development and validation. J Chronic Dis. 1987;40:373-83

11. Chikwe J, Adams DH. Frailty: the missing element in predicting operative mortality. Semin Thorac Cardiovasc Surg. 2010;22:109-10.

12. Cleveland JC Jr. Frailty, aging, and cardiac surgery outcomes: the stopwatch tells the story. J Am Coll Cardiol. 2010;56:1677-8.

13. Lee DH, Buth KJ, Martin BJ, Yip AM, Hirsch GM. Frail patients are at increased risk for mortality and prolonged institutional care after cardiac surgery. Circulation. 2010;121:973-8.

14. Sundermann S, Dademasch A, Praetorius J, Kempfert J, Dewey T, Falk V, et al. Comprehensive assessment of frailty for elderly high-risk patients undergoing cardiac surgery. Eur J Cardiothorac Surg. 2011;39:33-7.

15. Lytle BW, Blackstone EH, Sabik JF, Houghtaling P, Loop FD, Cosgrove DM. The effect of bilateral internal thoracic artery grafting on survival during 20 postoperative years. Ann Thorac Surg. 2004;78:2005-14; discussion, 14. 

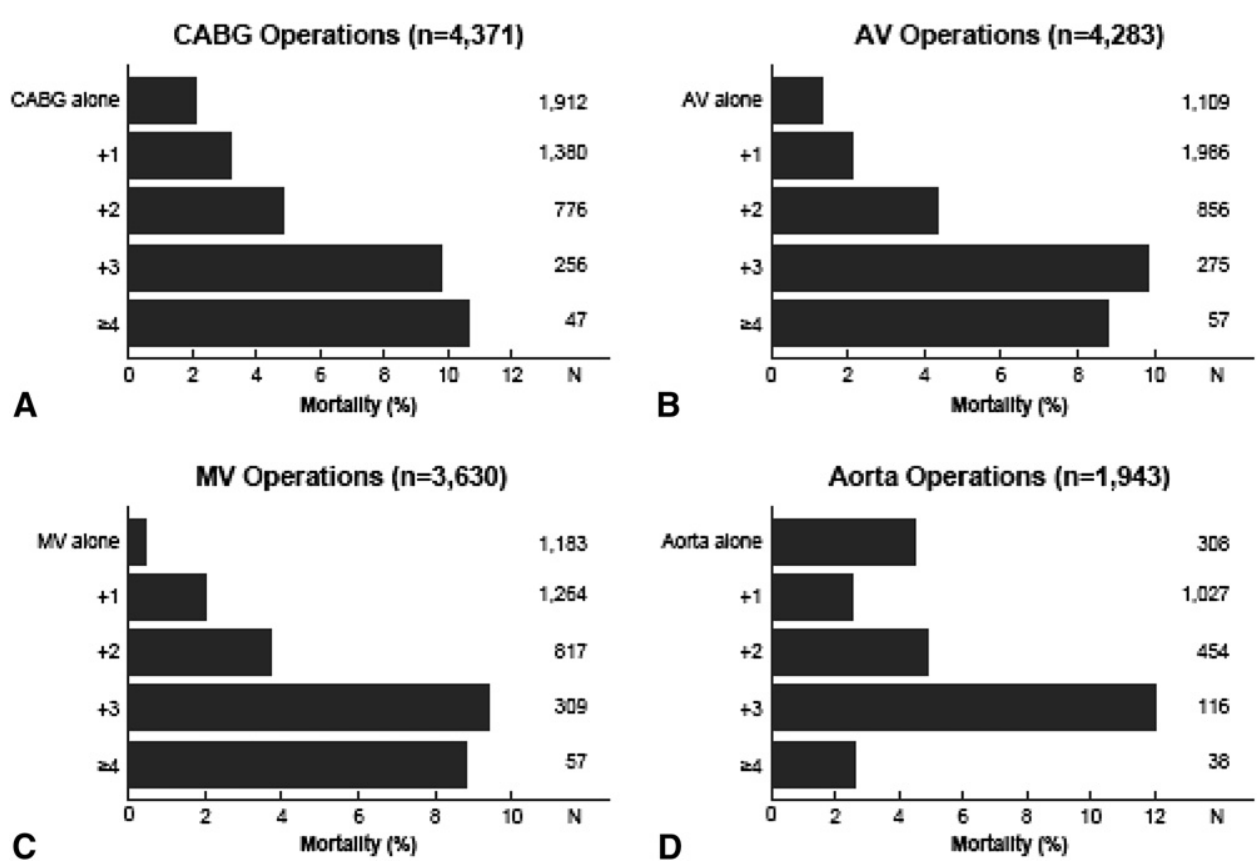

FIGURE 10. Hospital mortality according to number of surgical components for operations including (A) coronary artery bypass grafting (CABG), (B) aortic valve procedure $(A V),(\mathrm{C})$ mitral valve procedure $(M V)$, or $(\mathrm{D})$ aortic root, ascending aorta, or arch procedure. 

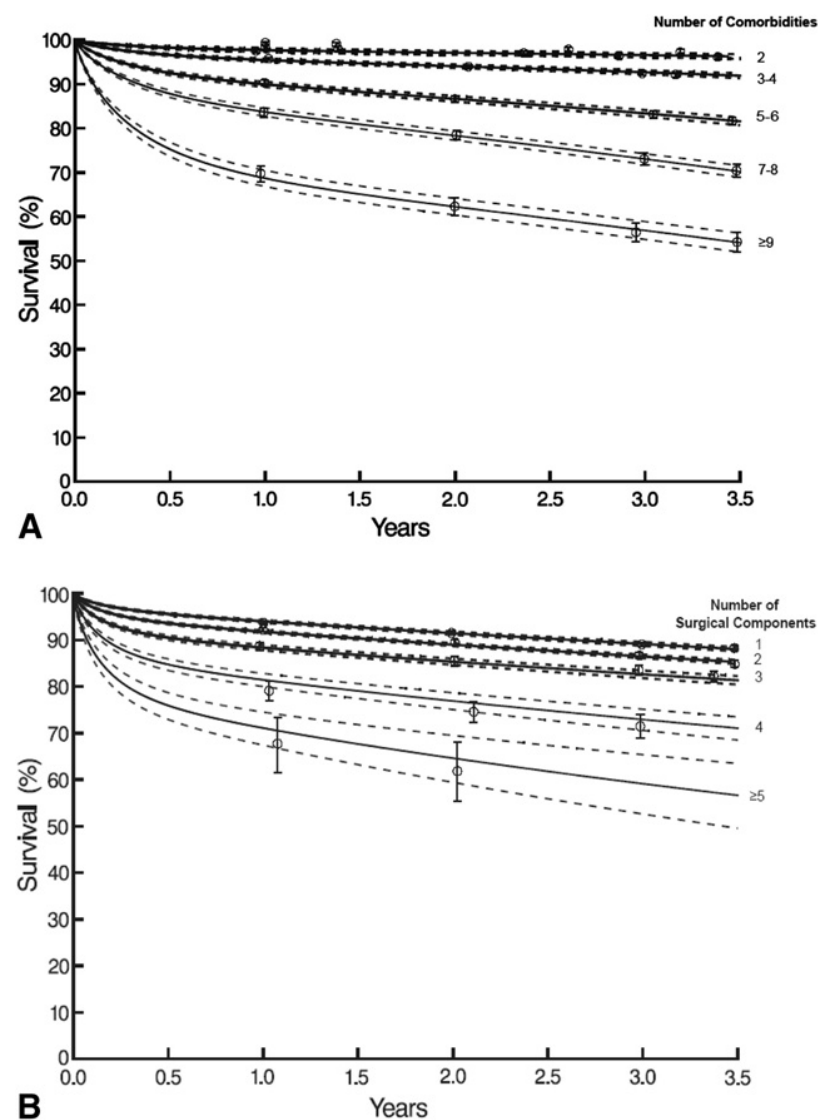

FIGURE 11. Survival after cardiac operations. Symbols at yearly intervals are Kaplan-Meier estimates accompanied by vertical bars representing asymmetric confidence limits equivalent to \pm 1 standard error. Solid lines within dashed confidence bands represent parametric estimates. A, Unadjusted mortality stratified by the number of patient comorbidities $(0-1,2$, $3-4,5-6,7-8$, or $\geq 9$; because of the small number of events in the 0-1 group, there are no parametric estimates). B, Unadjusted mortality stratified by the number of surgical components $(1,2,3,4$, or $\geq 5)$.

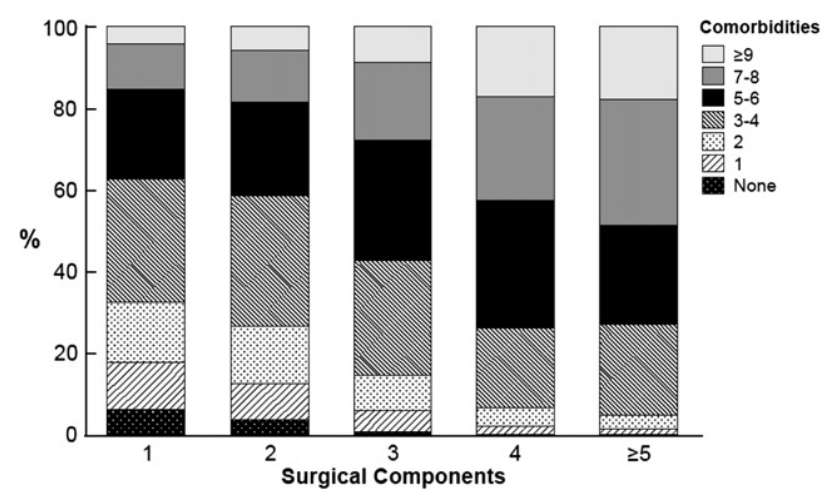

FIGURE 12. Percentage of patients in each patient complexity group (as demonstrated by number of comorbidities) undergoing 1-, 2-, 3-, 4-, or $\geq 5$ component operations.
BOX 1. Coronary artery bypass grafting combinations with 5 or more operations performed

$$
\begin{aligned}
& \text { Isolated CABG } \\
& \text { CABG }+1 \text { component } \\
& +\mathrm{AV} \\
& +\mathrm{MV} \\
& +\mathrm{TV} \\
& +\mathrm{AF} \\
& + \text { Aorta } \\
& \text { + Major LV procedure } \\
& + \text { Septal myectomy } \\
& \text { + Resection of atrial myxoma or tumor } \\
& + \text { Pericardiectomy } \\
& + \text { Heart transplant } \\
& \text { + Carotid endarterectomy } \\
& + \text { Transmyocardial (laser) revascularization } \\
& +\mathrm{ASD} / \mathrm{PFO} \\
& \mathrm{CABG}+2 \text { components } \\
& + \text { Aorta }+\mathrm{AV} \\
& + \text { Aorta }+ \text { MV } \\
& +\mathrm{AV}+\mathrm{AF} \\
& +\mathrm{AV}+\mathrm{MV} \\
& +\mathrm{MV}+\mathrm{AF} \\
& +\mathrm{MV}+\mathrm{ASD} / \mathrm{PFO} \\
& +\mathrm{MV}+\mathrm{TV} \\
& \text { + Major LV procedure + MV } \\
& + \text { Septal myectomy }+ \text { AV }
\end{aligned}
$$

$C A B G$, Coronary artery bypass grafting; $A V$, aortic valve surgery; $M V$, mitral valve surgery; $T V$, tricuspid valve surgery; $A F$, maze procedure (including non-cut-andsew maze); aorta, aortic root, ascending aorta, or arch replacement; $L V$, left ventricular; $A S D / P F O$, atrial septal defect or patent foramen ovale closure. 


\section{APPENDIX E1. Patient Complexity Components}

Eighteen dichotomous comorbidity components were chosen to characterize patient complexity as follows:

- Age $>75$ years

- Body mass index $>30 \mathrm{~kg} \cdot \mathrm{m}^{-2}$ (obese) or $<18.5 \mathrm{~kg} \cdot \mathrm{m}^{-2}$ (underweight)

- Acuity: emergency, preoperative intra-aortic balloon pump, cardiogenic shock, preoperative mechanical circulatory support, or inotrope support

- Previous myocardial infarction

- Reduced left ventricular function (ejection fraction $<50 \%$ )

- Arrhythmia: atrial or ventricular

- Heart failure: diagnosis within 2 weeks of surgery, paroxysmal nocturnal dyspnea, dyspnea on exertion, pulmonary edema, or medications for heart failure

- Cardiac reoperation

- Pharmacologically treated diabetes mellitus: oral agents or insulin

- Peripheral arterial disease

- Hypertension

- History of chronic obstructive pulmonary disease

- History of malignancy

- Renal failure: preoperative dialysis or creatinine $>2.5$ $\mathrm{mg} / \mathrm{dL}$

- Dyslipidemia: total cholesterol $>200 \mathrm{mg} / \mathrm{dL}$ or lowdensity lipoprotein $\geq 130$ or high-density lipoprotein $<40$

- Bilirubin $>1.0 \mathrm{mg} / \mathrm{dL}$

- Anemia: hematocrit $<35 \%$

- Cerebral vascular disease: stroke, transient ischemic attack, carotid stenosis $>75 \%$, prior carotid surgery
BOX E1. Aortic valve combinations with $\geq 5$ operations performed

Isolated $\mathrm{AV}$

$\mathrm{AV}+1$ component

+ Aorta

$+\mathrm{CABG}$

$+\mathrm{AF}$

$+\mathrm{ASD} / \mathrm{PFO}$

$+\mathrm{MV}$

$+\mathrm{TV}$

+ Septal myectomy

$\mathrm{AV}+2$ components

+ Aorta + CABG

+ Aorta $+\mathrm{MV}$

+ Aorta $+\mathrm{AF}$

+ Aorta + ASD/PFO

+ Aorta + TV

$+\mathrm{CABG}+\mathrm{AF}$

$+\mathrm{CABG}+\mathrm{CEA}$

$+\mathrm{MV}+\mathrm{AF}$

$+\mathrm{MV}+\mathrm{CABG}$

$+\mathrm{MV}+\mathrm{TV}$

$+\mathrm{TV}+\mathrm{AF}$

+ Septal myectomy + CABG

+ Septal myectomy + MV

$\mathrm{AV}+3$ components

+ Aorta + MV + CABG

+ Aorta $+\mathrm{MV}+\mathrm{TV}$

+ Aorta + MV + AF

$+\mathrm{MV}+\mathrm{CABG}+\mathrm{AF}$

$+\mathrm{MV}+\mathrm{TV}+\mathrm{AF}$

$+\mathrm{MV}+\mathrm{TV}+\mathrm{CABG}$

$\mathrm{AV}+4$ components

+ Aorta $+\mathrm{CABG}+\mathrm{MV}+\mathrm{TV}$

+ Aorta $+\mathrm{CABG}+\mathrm{MV}+\mathrm{AF}$

$+\mathrm{CABG}+\mathrm{MV}+\mathrm{TV}+\mathrm{AF}$

$A V$, Aortic valve surgery; aorta, aortic root, ascending aorta, or arch replacement; $C A B G$, coronary artery bypass grafting; $A F$, maze procedure (including non-cutand-sew maze); $A S D / P F O$, atrial septal defect or patent foramen ovale closure; $M V$, mitral valve surgery; $T V$, tricuspid valve surgery; $C E A$, carotid endarterectomy. 
BOX E2. Mitral valve combinations with $\geq 5$ operations performed Isolated MV

MV + 1 component

$+\mathrm{CABG}$

$+\mathrm{AV}$

$+\mathrm{TV}$

$+\mathrm{AF}$

+ Aorta

+ Septal myectomy

$+\mathrm{ASD} / \mathrm{PFO}$

$\mathrm{MV}+2$ components

+ Aorta $+\mathrm{AV}$

+ Aorta + CABG

$+\mathrm{AV}+\mathrm{AF}$

$+\mathrm{AV}+\mathrm{CABG}$

$+\mathrm{AV}+\mathrm{TV}$

$+\mathrm{CABG}+\mathrm{AF}$

$+\mathrm{CABG}+\mathrm{ASD} / \mathrm{PFO}$

$+\mathrm{CEA}+\mathrm{AF}$

$+\mathrm{TV}+\mathrm{AF}$

$+\mathrm{TV}+\mathrm{ASD} / \mathrm{PFO}$

$+\mathrm{TV}+\mathrm{CABG}$

+ Major LV procedure + CABG

+ Septal myectomy + AV

+ Septal myectomy $+\mathrm{AF}$

$\mathrm{MV}+3$ components

+ Aorta $+\mathrm{AV}+\mathrm{CABG}$

+ Aorta $+\mathrm{AV}+\mathrm{TV}$

+ Aorta + AV + AF

$+\mathrm{AV}+\mathrm{CABG}+\mathrm{AF}$

$+\mathrm{AV}+\mathrm{TV}+\mathrm{AF}$

$+\mathrm{AV}+\mathrm{TV}+\mathrm{CABG}$

$+\mathrm{TV}+\mathrm{CABG}+\mathrm{AF}$

$+\mathrm{TV}+\mathrm{CEA}+\mathrm{AF}$

$\mathrm{MV}+4$ components

$+\mathrm{CABG}+\mathrm{AV}+\mathrm{TV}+\mathrm{AF}$

+ Aorta $+\mathrm{CABG}+\mathrm{AV}+\mathrm{TV}$

+ Aorta $+\mathrm{CABG}+\mathrm{AV}+\mathrm{AF}$

+ Aorta + $\mathrm{AV}+\mathrm{TV}+\mathrm{AF}$

$M V$, Mitral valve surgery; $C A B G$, coronary artery bypass grafting; $A V$, aortic valve surgery; $T V$, tricuspid valve surgery; $A F$, maze procedure (including non-cut-andsew maze); aorta, aortic root, ascending aorta, or arch replacement; $A S D / P F O$, atrial septal defect or patent foramen ovale closure; $C E A$, carotid endarterectomy.
BOX E3. Aorta combinations with $\geq 5$ operations performed

Isolated aorta

Aorta +1 component

$+\mathrm{CABG}$

$+\mathrm{AV}$

$+\mathrm{MV}$

$+\mathrm{ASD} / \mathrm{PFO}$

Aorta +2 components

$+\mathrm{AV}+\mathrm{CABG}$

$+\mathrm{AV}+\mathrm{MV}$

$+\mathrm{AV}+\mathrm{TV}$

$+\mathrm{MV}+\mathrm{CABG}$

$+\mathrm{AV}+\mathrm{AF}$

$+\mathrm{AV}+\mathrm{ASD} / \mathrm{PFO}$

Aorta +3 components

$+\mathrm{AV}+\mathrm{MV}+\mathrm{CABG}$

$+\mathrm{AV}+\mathrm{TV}+\mathrm{CABG}$

$+\mathrm{AV}+\mathrm{MV}+\mathrm{TV}$

$+\mathrm{AV}+\mathrm{MV}+\mathrm{AF}$

$+\mathrm{AV}+\mathrm{CABG}+\mathrm{AF}$

$+\mathrm{AV}+\mathrm{CABG}+\mathrm{ASD} / \mathrm{PFO}$

Aorta +4 components

$+\mathrm{AV}+\mathrm{MV}+\mathrm{TV}+\mathrm{CABG}$

$+\mathrm{AV}+\mathrm{MV}+\mathrm{CABG}+\mathrm{AF}$

$+\mathrm{AV}+\mathrm{MV}+\mathrm{TV}+\mathrm{AF}$

Aorta, Aortic root, ascending aorta, or arch replacement; $C A B G$, coronary artery bypass grafting; $A V$, aortic valve surgery; $M V$, Mitral valve surgery; $A S D / P F O$, atria septal defect or patent foramen ovale closure; $T V$, tricuspid valve surgery; $A F$, maze procedure (including non-cut-and-sew maze). 
TABLE E1. Preoperative patient complexity risk model

\begin{tabular}{|c|c|c|}
\hline Parameter & Estimate $\pm \mathrm{SE}$ & $\boldsymbol{P}$ \\
\hline \multicolumn{3}{|l|}{ Demography } \\
\hline Older age* & $0.58 \pm 0.029$ & $<.0001$ \\
\hline Female & $0.49 \pm 0.047$ & $<.0001$ \\
\hline Lower BSA $\dagger$ & $1.4 \pm 0.32$ & $<.0001$ \\
\hline \multicolumn{3}{|l|}{ Acuity } \\
\hline \multicolumn{3}{|l|}{ NYHA class (vs I) } \\
\hline II & $-0.55 \pm 0.059$ & $<.0001$ \\
\hline III & $0.15 \pm 0.062$ & .02 \\
\hline IV & $0.18 \pm 0.057$ & .002 \\
\hline Emergency operation & $1.6 \pm 0.064$ & $<.0001$ \\
\hline Preoperative MCS & $3.3 \pm 0.11$ & $<.0001$ \\
\hline \multicolumn{3}{|l|}{ Cardiac comorbidity } \\
\hline Previous MI & $0.16 \pm 0.043$ & .0003 \\
\hline \multicolumn{3}{|c|}{ Degree of LV dysfunction (vs none) } \\
\hline Mild & $-0.0088 \pm 0.060$ & .9 \\
\hline Moderate & $0.39 \pm 0.061$ & $<.0001$ \\
\hline Severe & $0.55 \pm 0.071$ & $<.0001$ \\
\hline Atrial fibrillation & $0.14 \pm 0.062$ & $<.0001$ \\
\hline Complete heart block & $0.40 \pm 0.093$ & $<.0001$ \\
\hline \multicolumn{3}{|c|}{ Number of cardiac operations (vs 1 ) } \\
\hline 2 & $0.61 \pm 0.048$ & $<.0001$ \\
\hline 3 & $0.87 \pm 0.089$ & $<.0001$ \\
\hline$\geq 4$ & $0.83 \pm 0.18$ & $<.0001$ \\
\hline \multicolumn{3}{|l|}{ Noncardiac comorbidity } \\
\hline Diabetes & $0.19 \pm 0.056$ & .0004 \\
\hline Peripheral arterial disease & $0.22 \pm 0.055$ & $<.0001$ \\
\hline Hypertension & $0.11 \pm 0.050$ & .03 \\
\hline COPD & $0.37 \pm 0.061$ & $<.0001$ \\
\hline Smoking & $0.11 \pm 0.043$ & .01 \\
\hline Higher BUN $\ddagger$ & $0.74 \pm 0.054$ & $<.0001$ \\
\hline Lower cholesterol $\S$ & $0.56 \pm 0.074$ & $<.0001$ \\
\hline Higher bilirubin $\ddagger$ & $0.39 \pm 0.041$ & $<.0001$ \\
\hline Lower hematocrit $\ddagger$ & $-0.53 \pm 0.17$ & .001 \\
\hline Stroke & $0.15 \pm 0.066$ & .02 \\
\hline \multicolumn{3}{|l|}{ Experience } \\
\hline Earlier date of operation $\mid$ & $-0.055 \pm 0.017$ & .001 \\
\hline Intercept & $-6.2 \pm 0.71$ & $<.0001$ \\
\hline
\end{tabular}

$\mathrm{C}=0.81$. SE, Standard error; BSA, body surface area; NYHA, New York Heart Association; $M C S$, mechanical circulatory support; $M I$, myocardial infarction; $L V$, left ventricular; $C O P D$, chronic obstructive pulmonary disease; $B U N$, blood urea nitrogen. *Exponential transformation, exp(age/50). †Inverse squared transformation, $1 / \mathrm{bsa}^{2}$. †LLogarithmic transformation. §Inverse transformation, 200/cholesterol. ||Years from January, 1, 1967.
TABLE E2. Logistic model for hospital death incorporating surgical components

\begin{tabular}{lcc}
\hline \multicolumn{1}{c}{ Procedure } & Estimate \pm SE & $\boldsymbol{P}$ \\
\hline Pericardiectomy & $1.26 \pm 0.22$ & $<.0001$ \\
Major LV procedure & $1.11 \pm 0.11$ & $<.0001$ \\
Atrial myxoma & $0.88 \pm 0.33$ & .007 \\
Carotid endarterectomy & $0.88 \pm 0.11$ & $<.0001$ \\
Septal myectomy & $0.62 \pm 0.20$ & .002 \\
Aorta & $0.84 \pm 0.075$ & $<.0001$ \\
AV & $0.21 \pm 0.050$ & $<.0001$ \\
MV & $0.40 \pm 0.052$ & $<.0001$ \\
CABG & $0.31 \pm 0.052$ & $<.0001$ \\
AF & $-0.26 \pm 0.17$ & .12 \\
TV & $0.14 \pm 0.082$ & .10 \\
Transplant & $-0.003 \pm 0.15$ & .9 \\
Transmyocardial revascularization & $-0.14 \pm 0.60$ & .8 \\
Atrial septal defect or patent foramen ovale & $-0.21 \pm 0.20$ & .3 \\
$\quad$ closure & & \\
Preoperative risk & $0.97 \pm 0.016$ & $<.0001$ \\
Intercept & $-0.59 \pm 0.075$ & $<.0001$ \\
\hline C
\end{tabular}

$\mathrm{C}=0.82 . S E$, Standard error; $L V$, left ventricle; aorta, aortic root, ascending aorta, or arch replacement; $A V$, aortic valve surgery; $M V$, mitral valve surgery; $C A B G$, coronary artery bypass grafting; $A F$, maze procedure (including non-cut-and-sew maze); $T V$, tricuspid valve surgery. 